\title{
Estados Emocionais de Idosas a Partir do Teste de Apercepção Temática
}

\author{
Claudia Dallagnol \\ Eluisa Bordin Schmidt \\ Universidade Regional Integrada do Alto Uruguai e das Missões \\ Erechim, RS, Brasil \\ Irani I. de Lima Argimon \\ Pontificia Universidade Católica do Rio Grande do Sul \\ Porto Alegre, RS, Brasil
}

\begin{abstract}
RESUMO
Esta pesquisa teve como objetivo investigar estados emocionais em 10 idosas de 70 a 80 anos, participantes de um grupo de terceira idade. Foi realizado um estudo qualitativo tendo como instrumentos: Teste de Apercepção Temática, Mini Exame do Estado Mental e um questionário sociodemográfico. Foi realizada análise de conteúdo conforme método de Bellak. Como resultado as idosas expressaram necessidades internas de cumprimento do papel materno e emoções que apontaram para o desejo de se manterem ativas, felizes e altruístas, com necessidade de valorização, apoio e ajuda. Revelaram ansiedades vinculadas ao medo de perdas, solidão, dependência, sentimento de incapacidade e preocupação em relação ao futuro. Demonstraram estruturação de ego saudável e superego flexível. Concluiu-se também que o TAT permite a investigação e análise de aspectos emocionais da personalidade em idosas e possibilita uma compreensão psicodinâmica do funcionamento psicológico presente no envelhecimento.
\end{abstract}

Palavras-chave: Iidosas. Estados emocionais. Teste de Apercepção Temática.

\section{ABSTRACT}

Emotional States of Elderly Women Using the Thematic Apperception Test

The aimed of this study was to investigate emotional states of 10 elderly women aged between 70 and 80 years, members of an elderly group. It was conducted a qualitative study having as instruments the Thematic Apperception Test (TAT), the Mini Mental State Examination and a sociodemographic questionnaire. The analysis was performed with content analysis by Bellack method. As a result, the women expressed internal needs of keep themselves complying with the maternal role. They also showed emotions that point to the desire of keeping themselves activate, happy and altruistic, as well as needing valorization, support and help. Furthermore, they revealed anxieties associated to fear of loss, loneliness, dependency, feeling of being incapable and concerns about the future. They showed a healthy ego structure and a flexible superego. It's concluded that TAT allows the investigation and analysis of emotional states of personality in elderly women, also permitting a psychodynamic comprehension of the psychological functioning of aging.

Keywords: Elderly women. Emotional states. Thematic Apperception Test.

\section{RESUMEN}

\section{Estados Emocionales de Ancianas a Contar del Test Apercebimiento Temático}

Este trabajo ha tenido por finalidad investigar estados emocionales em 10 ancianas de 70 a 80 años, integrantes de un grupo de tercera edad. Ha sido efectuado um studio cualitativo con los siguientes instrumentos: Test de Apercibimiento Temático (TAT), Mini Examen del Estado Mental y um cuestionario sociodemográfico.El análisis de su contenido ha sido realizado según el método de Bellak. Como resultado, las ancianas han expresado necesidades interiores de cumplir el rol materno y emociones que señalaron para el deseo de mantenerse activas, dichosas y altruistas, com necesidad de valoración, apoyo y ayuda. Ellas han revelado ansiedades vinculadas al temor de pérdidas, soledad, dependencia, sentimiento de incapacidad y preocupacin respecto al porvenir. Han demonstrado también estructuracion de ego saludable y superego flexible. Se ha llegado a conclusión de que el TAT permite la investigación y el análisis de aspectos emocionales de la personalidad en ancianas, posibilitando una comprensión sicodinámica del funcionamento sicológico presente al proceso de envejecer.

Palabras clave: Ancianas. Estados emocionales. Test de Apercibimiento Temático. 


\section{INTRODUÇÃO}

Conforme estatísticas recentes, o crescimento acelerado da população idosa apresenta-se como um fator que evidencia a importância de atualizações do saber e de qualificações na assistência ao sujeito presente nesta etapa da vida. O elevado crescimento dessa massa populacional, que ocorre principalmente pelo decréscimo das taxas de natalidade e pelo aumento da perspectiva de vida dos idosos (Gaglietti e Barbosa, 2007), representa um progresso em nível de perspectiva de vida nacional, bem como produz mudanças consideráveis na realidade social, política e científica (Papaléo Neto 2007a). Segundo dados do IBGE (2009), no Brasil este novo padrão demográfico tende a se alargar com o passar dos anos e estudos voltados para o envelhecimento vêm crescendo e ganhando espaço nas discussões atuais.

Para Neri (2005), o aumento da perspectiva de vida dos idosos se deve também em grande parte aos progressos sociais e aos avanços da ciência porém, muito ainda precisa ser alcançado no que se refere ao envelhecimento enfatizando a necessidade da ampliação e da construção de modelos explicativos para esta fase, os quais viabilizam uma melhor compreensão do mesmo e contribuem para a integração da velhice como um processo do curso de vida.

Para a Organização Mundial da Saúde (2011), são considerados idosos, indivíduos a partir dos 60 anos nos países em desenvolvimento e 65 anos em países desenvolvidos. Entretanto, conforme Neri, (2005) e Papaléo Neto (2007b), a passagem para a velhice não é estanque, nem mesmo apenas cronológica, mas constitui-se por um conjunto de atributos que são despertados com o processo de envelhecimento.

Por envelhecimento entende-se a última etapa do desenvolvimento humano, configurado por alterações orgânicas, neurobiológicas e funcionais. Não menos, também incidem influência sobre o indivíduo fatores ambientais e socioculturais como apontam Santos, Andrade e Bueno (2009). Do ponto de vista conceitual, idoso, velho ou terceira idade são diferentes nomenclaturas que designam o mesmo processo, ou seja, o envelhecimento é um período do ciclo vital dinâmico e heterogêneo, marcado por questões de gênero, cultura, condições individuais e sociais (Ferrari, 2007).

Segundo Silva (2008), o envelhecimento pensado na contemporaneidade, e enredado por manifestações culturais, é repercutido por mudanças que vão além da quietude, do descanso e da inatividade até então representativos deste processo para compreender novas práticas que caracterizam a atividade, a aprendizagem, a flexibilidade, a satisfação pessoal e a vinculação amorosa e afetiva como associadas. Hoje, tal ampliação da representação produz um aumento das descrições do envelhecimento visto que a velhice se somou a terceira idade, ganhando novas significações.

Contudo, não raramente a velhice é administrada como algo alheio, que causa medo e imobiliza, a qual vai contra os princípios e padrões da cultura vigorante e gera ansiedade, aspectos que levam a perdas, dificuldades e limitações da fase. Ainda, ela traz consigo mudanças que demonstram vulnerabilidade e disfunções, tanto físicas quanto psíquicas, mas seu desfecho se dá de acordo com a personalidade e com os recursos que dispõe cada sujeito (Aranha, 2007).

Papaléo Neto (2007a) considera que o desejo de ter uma velhice saudável é uma pretensão antiga, de modo que essa preocupação esteve presente em construções teóricas nos mais diversos períodos da história da humanidade. Aponta o cuidado com a preservação da saúde e da independência física e bom estado cognitivo. Conjuntamente aparecem as preocupações referentes a preservação da atividade, da produtividade e dos papéis sociais.

Os declínios na velhice não obedecem a um mesmo padrão evolutivo, pois ocorrem em diferentes ritmos, a própria velhice considerada como bem-sucedida comporta mudanças, que não são patológicas, mas incluem doenças que não causam impedimentos funcionais. Mesmo na presença de doenças e agravos afetivos e sociais, o idoso pode viver bem sua velhice, desde que acione recursos pessoais e estratégias de enfrentamento (Caldas, 2007).

Deste modo, cabe considerar que a velhice bem sucedida se apresenta nos idosos que mantêm autonomia, independência, envolvimento ativo com a vida pessoal, família, amigos, lazer, vida social, produtividade e conservação de papéis sociais. Além disso, também se destaca como fator de bem estar na velhice a auto-aceitação, o altruísmo, as relações positivas, os estados afetivos e a funcionalidade física e espiritual (Capitanini e Neri 2004; Neri, 2004).

A manutenção de papéis sociais, dos vínculos afetivos e as estratégias preventivas para evitar sintomas ou doenças psíquicas são sinônimas de envelhecimento bem sucedido. Também, destaca-se o estilo de vida ativo que repercute no bom desempenho físico e mental, favorecendo a administração da própria vida e dos eventos do mundo externo (Argimon; Manfredini; Gindri; Pereida e Farina, 2009).

Um estudo de Argimon et al.(2009), realizado com o objetivo de identificar a influência das variáveis sexo e idade nos sintomas depressivos em idosos, constatou que não há diferença significativa de tais fatores. 
Com relação a idade, é possível identificar um índice significativo de sintomas depressivos na população adulta feminina, entretanto com o envelhecimento esta prevalência não se mantêm. Desse modo, identificouse que sexo e idade não são fatores protetivos nem mesmo de vulnerabilidade para sintomas de depressão em ambos os sexos em idosos. Por outro lado, esse estudo observou que a escolaridade apresenta-se como um fator protetivo, uma vez que as características depressivas se apresentaram em menor intensidade em idosos com escolaridade mais elevada.

A integridade dos processos intelectuais e da continuidade dos mecanismos de autorregulação da personalidade é importante na determinação da longevidade e da boa qualidade de vida na velhice. Estes mecanismos sob alguns aspectos permanecem intactos, o que garante a continuidade do funcionamento psicossocial e propicia bem estar subjetivo ao idoso, assim a personalidade e o self mudam pouco na velhice mesmo que sob qualquer variável (Neri, 2004).

Papalia, Olds e Feldman (2006), do mesmo modo, assinalam que dentre as características do envelhecimento está a tendência à estabilidade dos traços de personalidade com a velhice. Além disso, referem que não é verídica a ideia culturalmente construída que na velhice as pessoas ficam mais retraídas e reprimidas, o que há é estabilidade da personalidade.

Conforme Caldas (2007), outra fonte de estabilidade da personalidade adulta está na tendência a optar por ambientes de acordo com o sujeito, aqueles espaços que demandem menos mudanças. Joia, Ruiz e Donalisio (2007) identificaram fatores associados a sensação de conforto e de bem estar, além de saúde e independência como aspectos determinantes de felicidades.

Uma das técnicas de investigação da personalidade é o Teste de Apercepção Temática, conhecido como TAT, que foi criado por Henry A. Murray em 1935, constituindo-se como um método de investigação psicológica que se destina a investigar impulsos, emoções, sentimentos, complexos e conflitos marcantes da personalidade do indivíduo. Sua principal função está na possibilidade de tornar acessíveis tendências subjacentes inibidas que o indivíduo por vezes não deseja aceitar, ou mesmo, não tem condição de admitir por serem inconscientes (Murray, 1995).

Por meio do TAT é possível coletar informações que levam ao conhecimento de aspectos importantes da personalidade do sujeito. Consiste em apresentar uma série de quadros ao indivíduo, estimulando-o a contar histórias baseadas neles. O processo pelo qual as pessoas revelam componentes de sua personalidade se dá na medida em que interpretará a situação dos quadros baseando-se em suas próprias experiências passadas e anseios presentes, além das pessoas contarem histórias que retratam a sua própria forma de sentir e agir (Murray, 1995).

O teste é formado por quadros com ilustrações que foram organizadas com estímulos considerados universais, que se aplicariam a sujeitos de ambos os sexos e de diferentes faixas etárias, e outros, com estímulos específicos para o sexo e idade dos sujeitos. Cada quadro tem uma ilustração com exceção do quadro 16 que se apresenta em branco. A análise parte do pressuposto que a percepção dos estímulos (quadros) é assimilada e transformada pelos conteúdos de experiências anteriores que produzem nova organização perceptiva cheia de significados advindos da dinâmica do sujeito (Silva \&Montagna, 2008).

Segundo a composição do TAT proposta por Murray (1995), o teste possui trinta e um quadros com cenas de personagens humanos em diversas situações, sendo que como a seleção dos quadros é realizada de acordo com a idade e sexo do sujeito, segundo o método de Murray são aplicados vinte quadros.

Para Abt e Bellak,(1950) a primeira vista os estímulos recebem determinada interpretação que é a tida como norma, porém a atribuição de sentimentos não é a percepção da norma, mas sim a atribuição de conteúdos pessoais. Este autor propõe uma forma de análise de conteúdo do material onde se busca a identificação de padrões de comportamento recorrentes ao sujeito ao administrar as diferentes situações dos estímulos do TAT. Este processo é analisado através da história produzida em cada quadro, ou seja, são avaliados os temas apresentados, o enredo, os personagens, o contexto, as relações entre os personagens e suas caracterizações, bem como as tensões dinâmicas.

De acordo com Bellak e Abrams (1996) pode ser utilizada uma forma de aplicação reduzida do TAT, com um conjunto de dez quadros, evidenciando assim a possibilidade de aplicar menos quadros e obter bons resultados. Conforme Werlang (2000), além dos critérios de idade e sexo, outros aspectos podem ser critérios de escolha dos quadros, como a suscetibilidade ou vulnerabilidade dos mesmos mobilizarem mais facilmente determinadas situações, problemas e aspectos dinâmicos do sujeito.

Desde 2003 o TAT é um teste aprovado pelo Conselho Federal de Psicologia (2010) sendo assim, permitida sua utilização tanto para avaliação clínica quanto para fins de pesquisa. Campos, Bach e Alvares (2003) utilizaram dois quadros do TAT para levantar os estados emocionais de sujeitos submetidos a transplante de medula óssea e consideraram resultados significativos com o método de coleta utilizado. 
Segundo os autores deste estudo, o TAT possibilitou uma investigação mais profunda dos movimentos psicodinâmicos dos pacientes, além de ter propiciado a manifestação de aspectos emocionais que evidenciaram o estado emocional dos indivíduos naquele momento.

Werlang (2000) descreve conceitos do autor Leopold Bellak que propôs o sistema psicodinâmico de interpretação do TAT definido através da compreensão dos mecanismos que levam um indivíduo a expressar aspectos da sua personalidade através deste teste psicológico. Bellak (1967b, 1979 citado por Werlang, 2000), utilizou os conceitos de projeção, percepção e apercepção. Segundo ele, os resíduos das experiências vivenciadas pelos sujeitos influenciam na percepção e projeção nas novas experiências. No caso do teste que é composto por quadros mobilizadores, a percepção e a projeção influenciam na produção das histórias e para conceituar o processo através do qual uma experiência é assimilada e transformada pelos vestígios da experiência passada do sujeito, ele utilizou o termo apercepção que em outras palavras seria a interpretação subjetiva, dinamicamente organizada e permeada pelo significado pessoal de cada indivíduo. Esta apercepção, por sua vez, é que possibilita a expressão de estados emocionais de cada sujeito.

Existem diferentes formas de análise dos conteúdos mobilizados pelo TAT. No sistema de interpretação de Bellak, a análise do TAT tem foco principal no conteúdo das respostas verbalizado pelo sujeito. Neste formato é possível utilizar a psicanalítica, dirigida para as funções do ego, mecanismos de defesa e relação entre os processos primários e secundários (Werlang, 2000). Neste estudo foi utilizada a abordagem psicanalítica.

Conforme Silva e Montagna (2008) apresentam, o método de interpretação de Bellak procura identificar padrões de comportamento, sendo este processo realizado por meio da análise do conteúdo das histórias produzidas. Desta forma, Werlang (2000) aponta que o método interpretativo proposto por Bellak é constituído por categorias que são: tema principal, herói principal, necessidades e impulsos do herói, concepção do meio ambiente investigando as atitudes frente às figuras de vinculação, conflitos significativos, natureza das ansiedades, principais defesas, adequação do superego e desenlace das histórias que incluía a integração do ego.

Através de revisão de literatura constatou-se que nos últimos cinco anos existem poucos estudos realizados com o TAT associados com a população idosa, encontrando-se um estudo descrito por Benoit (2002) que desenvolveu uma pesquisa na qual utilizou do TAT com idosos e apontou que o teste é perfeitamente pertinente para demonstrar problemáticas que atuam no funcionamento psíquico do idoso.
Em vista do exposto e da compreensão que o campo de conhecimento ainda precisa se alastrar no que tange ao envelhecimento e ao uso do TAT como instrumento psicológico qualificado, pretende-se com este artigo apresentar os resultados de uma pesquisa que objetivou investigar e analisar através do TAT que estados emocionais estão presentes em idosas com idade entre 70 e 80 anos.

\section{MÉTODO}

Foi realizada uma pesquisa qualitativa, descritiva, com delineamento de corte transversal. Fizeram parte do estudo 10 idosas, com idade entre 70 e 80 anos, participantes de um grupo de terceira idade, da cidade de Erechim-RS, que não apresentaram prejuízos cognitivos e aceitaram participar voluntariamente do estudo.

Após a aprovação do projeto de pesquisa pelo Comitê de Ética da URI - Campus de Erechim foi efetuado um contato primeiramente com a coordenadora da entidade ao qual o grupo é vinculado a fim de viabilizar a autorização para a coleta de dados. Após o consentimento local, a coordenadora responsável pelo grupo estendeu o convite às idosas para participarem da pesquisa. As participantes foram selecionadas a partir de um sorteio com as que apresentavam os critérios de sexo e idade e a partir disso foi efetivada a coleta de dados, sendo previamente agendada e posteriormente realizada individualmente com cada participante.

No momento da coleta de dados inicialmente leu-se o termo de consentimento livre e esclarecido e em seguida a participante foi submetida à aplicação do Mini-Exame do Estado Mental. Se nessa triagem eram evidenciados déficits cognitivos, a candidata era encaminhada para um serviço de atendimento psicológico que oferecesse apoio, caso contrário, seguia até o final da coleta de dados. Nenhuma das candidatas sorteadas apresentou déficits avaliados pelo Mini Mental, portanto todas as sorteadas participaram da pesquisa. Na sequência, foram aplicados cinco quadros do teste TAT, sendo que toda a história relatada em cada quadro foi escrita pela pesquisadora durante o relato da mesma, conforme pressupõe as normas de aplicação do teste. Por fim, foi aplicado o questionário sociodemográfico. Para garantir o anonimato da identidade das participantes, as mesmas foram nominadas de A1 até A10.

Os instrumentos utilizados foram: Mini-Exame do Estado Mental, cinco quadros do Teste de Apercepção Temática - TAT e um questionário sociodemográfico. O instrumento Mini-Exame do Estado Mental foi utilizado para identificar a condição mental das idosas 
para participar da pesquisa, este instrumento fornece uma avaliação quantitativa do desempenho e da capacidade cognitiva do indivíduo e é útil para avaliar e quantificar a gravidade do prejuízo cognitivo (Erné, 2000).

Nesta pesquisa os cinco quadros foram selecionados de acordo com os aspectos que poderiam mobilizar expressões das experiências emocionais no envelhecimento. Foram aplicados os quadros 2, $8 \mathrm{MF}$, $12 \mathrm{~F}, 19$ e 16, na respectiva ordem, escolhidos conforme os aspectos mobilizadores de cada quadro descritos por Shentoub et al. (1990), que poderiam investigar aspectos emocionais e questões referentes ao processo de envelhecimento.

O quadro 2, considerado universal, representa uma cena campestre com três personagens. Há no primeiro plano uma jovem carregando livros nas mãos, no fundo um homem trabalhando com um cavalo no campo e uma mulher mais velha como espectadora da cena encostada numa árvore. De acordo com Shentoub et al. (1990), o quadro remete à relação pai-mãefilha e coloca em prova a organização edipiana e sua característica mais ou menos estruturante.

No quadro $8 \mathrm{MF}$, destinado à população feminina, há uma mulher descansando, segurando o queixo e olhando no vazio. Conforme Silva (1989), este quadro evoca questões referentes aos conflitos atuais. $\mathrm{O}$ quadro $12 \mathrm{~F}$ também destinado ao grupo feminino, retrata uma jovem senhora no plano da frente com uma velha estranha com um xale na cabeça fazendo careta no fundo. Para Silva (1989), tal cena remete à relação mãe filha, à crítica ou aceitação do modelo materno e ansiedade frente ao envelhecimento.

O quadro 19, considerado universal, se configura como estranho, visto que mostra a formação de nuvens, sobrepairando uma cabana coberta de neve no campo.Trata de estímulos desconcertantes e que levam à fantasia, refere a necessidade de proteção e amparo frente a um ambiente inóspito. O quadro 16, considerado universal, encontra-se em branco, de modo que o sujeito é levado a projetar-se, havendo uma expressão do reflexo da relação transferencial na situação do teste (Silva, 1989).

Por fim, aplicou-se um questionário sociodemográfico com o objetivo de coletar informações das participantes da pesquisa referentes a idade, data de nascimento, estado civil, escolaridade, religião, cidade em que reside, bairro, naturalidade, com quem reside, profissão, renda mensal, doenças que apresenta, se utiliza medicações, filiação, idade dos filhos, número de netos e estado civil.

Para a análise de conteúdo, fundamentou-se no método de interpretação proposto por Abt e Bellak (1950) que considera como foco principal o conteúdo das respostas, principalmente no que se refere à qualidade da produção e controle que o indivíduo mantém sobre a expressão e organização da resposta. As categorias que norteiam a análise proposta são: tema principal, herói principal, necessidades e impulsos do herói, conceito do meio ambiente investigando as atitudes frente às figuras de vinculação, conflitos significativos, natureza das ansiedades, principais defesas, adequação do superego e integração do ego. Em cada categoria foram relacionados os conteúdos verbalizados pelo sujeito em cada história criada para o estímulo apresentado. Desta forma, após a categorização realizada com cada uma das histórias de cada quadro dos participantes, foi feita a integração das categorias entre os sujeitos do estudo. A estas categorias foram integrados os dados sociodemográficos levantados pelo questionário, para fazer a análise das variáveis do teste TAT.

\section{RESULTADOS E DISCUSSÃO}

O questionário sociodemográfico aplicado identificou que metade das idosas da amostra eram viúvas e a outra metade casada ou separada, com variação na escolaridade do segundo ano do ensino fundamental ao ensino médio incompleto. De modo geral, não são naturais do local onde atualmente residem, possuem diferentes classes sociais, grande parte tem origem no meio rural e são preponderantemente praticantes da religião católica. Em relação às doenças que apresentam, a grande maioria tem problemas com hipertensão. Todas tiveram filhos, que variam de dois a sete. Há uma diferença em relação à com quem residem, sendo identificadas idosas que vivem sozinhas, outras com filhos e as casadas que vivem com os seus maridos.

Com base no teste TAT, os resultados serão apresentados conforme as categorias de análise propostas por Bellak (Silva e Montagna, 2008). No que se referem ao tema principal, as histórias trouxeram questões relativas a mulheres preocupadas e pensativas, envolvidas com relações familiares em diferentes momentos do desenvolvimento retratando experiências vivenciadas no ciclo vital de famílias, bem como os momentos da juventude e velhice. Os temas em geral se apresentaram num contexto rural, onde apareceram relatos de roças, bosques, árvores e montanhas. As idosas que participaram do estudo nasceram e viveram parte de suas vidas no meio rural, além disso, todas vivenciaram relações conjugais. Embora o estímulo principal do quadro 2 seja uma cena campestre, observou-se que as idosas enfatizaram o espaço rural nas histórias contadas, o que retrata o 
estabelecimento de uma relação com o meio ambiente em que nasceram e viveram parte de suas vidas.

Do mesmo modo estes dados percebidos sugerem que os quadros apresentados despertaram questões das relações familiares vivenciadas por elas ao longo de suas vidas, em que os fragmentos que permanecem reforçam uma ideia de preocupação com o momento de vida que perpassam, onde se mostram pensativas e relembrando fatos do passado, sendo isso uma preocupação constante, como foi descrito: É um quadro que fala sobre a familia? Eu acho que é trabalhadores que trabalham na roça. (A7 - quadro 2).

Conforme Ferrari (2007) o envelhecimento carrega consigo influências que tem origens culturais e sociais, que repercutem na forma como as idosas vivem tal processo, como foi identificado nos dados coletados.

$A i$, aqui deve ser eu, bem preocupada sempre pensando nos outros e não na gente, é um erro. Não pensando em mim. Eu me vejo nessa fotografia. Parecida com essa mulher, [...]. Na realidade nós vivemos numa época que dão pouco valor pro idoso, não são valorizados como deveriam. Porque foram batalhadoras e agora tem tudo na mão e nós não tinha isso. Não tinha água encanada, tinha que puxar água do poço, lavar roupa a mão, cortar lenha. Eu fiz isso no meu tempo. (A10 - quadro $8 \mathrm{MF})$.

Os resultados coletados identificaram aspectos característicos de apercepção, visto que em vários quadros apareceram expressões das participantes através das quais se identificaram e revelaram questões próprias, se colocando em primeira pessoa nas histórias contadas. Conforme Murray (1995) o processo através do qual o sujeito revela componentes de sua personalidade se dá pela interpretação da situação dos quadros, baseando-se em suas próprias experiências de vida e anseios presentes, retratando a sua forma de agir como foi descrito no a seguir: Ai aqui deve ser eu, [...]. Eu me vejo nessa fotografia. Parecida com essa mulher, [...] eu sou assim e ela deve ser também. (A10 - quadro 8MF).

Da mesma forma, na identificação dos personagens principais houve uma predominância da pessoa feminina, transcorrendo por vários momentos do desenvolvimento. As participantes do estudo se colocaram enquanto filhas, mulheres, grávidas, mães, idosas, com características de beleza, preocupação, pensativas, em alguns relatos angustiadas e em outros tranquilas. Este dado denota o quanto as idosas se apresentam neste momento da vida mobilizadas pelas mudanças biológicas e imbuídas por preocupações, pensamentos e angústias do processo que estão vivendo e do que está por vir, o que pode ser observado no trecho a seguir: [...] ela tá assim, pensativa (A2 - quadro 2). [...] a preocupação das mulheres, ela está muito pensativa (A3 - quadro 8MF). Mulher sentada, tranquila, pensativa [...] [...] todos aqui estão preocupados. [...] Todos preocupados com o amanhã. (A3 - quadro 2). Nessa perspectiva, Aranha (2007) aponta que com o envelhecimento, muitas mudanças acontecem e demonstram vulnerabilidades e disfunções, tanto físicas quanto psíquicas, sendo determinadas de acordo com a personalidade e recursos que dispõe o sujeito. Assim, considera-se que as questões vinculadas a beleza, preocupação, angústia, pensamentos e tranquilidades são naturais e se mostraram variáveis para cada sujeito da pesquisa, porém todas refletem as incertezas do período em que estão imersas. A história contada por uma das participantes frente ao quadro $12 \mathrm{~F}$, que mobiliza a ansiedade frente o envelhecimento, ilustra esta categoria:

Aqui retrata o hoje e o amanhã. Hoje é juventude, entusiasmo, é poder e é trabalho também. E o amanhã é uma caixinha de surpresas. Muitos idosos não são respeitados. Desrespeitados pelo poder público. Não tem acesso à saúde de acordo. Então, muitas vezes a própria família abandona o idoso. Isso gera dor, sofrimento, descaso, e ai vem a pergunta, será que eu não fiz o bastante na minha vida pra hoje poder ter um final mais feliz na minha vida? (A3 - quadro 12F).

Em relação a categoria que trata das principais necessidades e impulsos do herói, prevaleceram necessidades de cumprir o papel materno, mostrarse feliz, contemplar, refletir, de reconhecimento, valorização, onde preponderaram as questões de relacionamento familiar, nomeando um ambiente em que percebiam desejo de apoio, ajuda, com sentimentos de tristeza e solidão e de pensar na vida. Tais dados apontam para um momento em que as idosas expressaram a necessidade de manterem ativos os papéis desempenhados ao longo da vida, tendo ainda o desejo de finitude feliz, mesmo que perpassem momentos de tristeza, solidão e necessidade de ajuda.

Quanto à concepção do ambiente, as idosas descreveram ambientes calmos de relacionamento familiar, com a presença de descanso e contemplação, por outro lado apareceram também ambientes inseguros quanto ao futuro, desestruturados, assustadores, exigentes, com falta de recursos, falta de apoio familiar, desconhecidos, tristes, com sofrimentos. $\dot{E}$ uma casa construída numa região montanhosa tinha 
um homem na lavoura, uma mulher parada, uma moça saindo pra estuda, trabalhar. Não se vê rua, não se vê entrada, uma saída ou uma chegada. Um lugar ermo. (A4 - quadro 2).

Papaléo Neto (2007a) argumenta que o desejo de se ter uma velhice saudável existe sendo fatores importantes o cuidado com a preservação da saúde e da independência física e cognitiva, além da manutenção da autonomia. Conjuntamente aparecem as preocupações referentes à preservação da atividade, da produtividade e dos papéis sociais. Assim, sabe-se que a pretensão em se ter uma velhice saudável existe e é continuamente reforçada em nossa sociedade em que cada vez mais predomina o número de idosos. Esse fato foi aparente nos relatos das participantes do estudo que demonstram preocupações em se manterem ativas, exercendo papéis sociais e familiares, entretanto oscilam em momentos de necessidade de apoio, onde percebem falta de recursos e experimentam um sentimento de insegurança, tristeza e sofrimento advindo da percepção de suas fragilidades.

$\mathrm{Na}$ categoria conflitos significativos, os dados mostram questões vinculadas ao relacionamento conjugal, entre os pais e filhos, aspectos relacionados às questões de morte, incapacidade de dar conta das pressões do ambiente, conflito com relação a auto-imagem no que diz respeito à beleza, medo de abandono e sentimento de culpa pela possibilidade de ser abandonada, desejo de expressar tristeza porém reprimí-la como forma de evitar o sofrimento, busca de aprovação, valorização e reconhecimento.

Em relação à análise da categoria natureza das ansiedades as idosas revelaram através do conteúdo das suas histórias diversas ansiedades tais como: angústia e insegurança frente a situações descritas como difíceis, principalmente à situações vinculadas a perdas e danos físicos e psíquicos, frente a situações de morte, tristeza, solidão, separação e em pensar em viver sem filhos no próprio lar. Tais ansiedades podem ser observadas nas falas a seguir: Aqui retrata o hoje e o amanhã. [...]. E $o$ amanhã é uma caixinha de surpresas. Muitos idosos não são respeitados. [...]. (A3 - quadro 12F). Uma juventude exuberante e uma velhice triste, aparência de abandono [...]. (A8 - quadro 12F).

Além disso, as idosas descreveram ansiedades advindas de momentos que se colocam a pensar na vida, predominantemente diante da necessidade de fazer escolhas, se mostrar felizes e altruístas. O relato que segue ilustra: Essa daqui pelo jeito tá feliz. Essa daqui acho que tá com os oitenta anos que nem eu. Mas essa aqui pelo jeito tá feliz, pela idade dela e pelo companheiro dela, tão muito feliz. (A5 - quadro $12 \mathrm{~F})$.
Com base nos achados referentes aos conflitos significativos e natureza das ansiedades, constatou-se que o envelhecimento para as idosas pesquisadas é a vivência de um período da vida permeado por angústia frente ao desconhecido, onde os sentimentos e as emoções se revelaram de forma ambivalente, quando elas descreveram histórias com conteúdos e desfechos positivos, mas ao mesmo tempo expressaram emoções que elas próprias consideravam negativas, e quando no enredo das histórias descreveram um desejo de querer ajudar e estarem impossibilitadas, ou mesmo querer expressar a tristeza e reprimí-la para não sofrer.

Neste sentido Aranha (2007) considera que a velhice é tida como algo alheio, que gera medo e imobiliza, acarreta ansiedade e leva a se pensar em perdas, dificuldades e limitações da fase. Tais aspectos podem ser identificados nas idosas do estudo, que mostram dificuldade de dar conta das pressões do ambiente ao passo que expressam emoções da fase carregadas de muita angústia, impotência e medo. O enredo descrito principalmente no quadro 19 que apresenta um estímulo desconcertante e fantasioso, o qual mobiliza questões relacionadas a necessidade de proteção e amparo frente a um ambiente inóspito ilustra:Meu Deus, o que seria isso? [...] Mas deixa assim. Não entendi muito bem. (A10). É tudo tão inacabado, [...] Parece um vendaval. Bem misterioso. [...] Fim, eu não sei o que dá isso aqui. (A9).

Tendo em vista os conflitos e as ansiedades presentes, observa-se que as defesas utilizadas pelas participantes do estudo foram, de forma mais maciça e na sua ordem de maior presença, a repressão e a projeção, seguidas por negação, racionalização e idealização. Em menos proporção também apareceram mecanismos como identificação, fuga, formação reativa, deslocamento, sublimação, dissociação, anulação, atuação e isolamento. As defesas são utilizadas como recursos para dar conta das ansiedades que estão presentes (Zimerman, 1999), assim reprimir e projetar se constituíram como os principais recursos de defesa que as idosas utilizaram para dar conta das ansiedades despertadas no envelhecimento, ou seja, reservam algumas angústias a nível inconsciente e/ou atribuem aos outros os sentimentos inaceitáveis que carregam.

Em relação a adequação do superego, percebeuse que as idosas, no conteúdo de suas histórias, descreveram vivências com figuras de autoridade mais rígidas contudo seus desfechos permitiram a categorização dos superegos também mais flexíveis, o que pode indicar que com o passar do tempo as idosas do estudo se tornaram mais permissivas, aspecto que possibilitou uma adaptação mais facilitada para com 
as questões do envelhecimento. As falas a seguir demonstram a rigidez superegóica das idosas do estudo:

Naquele tempo a gente não tinha muita coisa, tinha que obedecer o que eles falavam. [...] Isso aqui é de tempo, que todo mundo tinha que obedecer as pessoas, se não prendiam. Dai quando a gente era criança ficava com medo quando se via umas pessoas assim, porque não sabia o que eles iam falar. E os pais não falavam nada pra gente. Eles não respondiam as perguntas. [...] Ele (pai) não comprava roupa, era ruim que nossa, mas eu admirava ele. (A7 - quadro 12F).

Contudo, Neri (2005) refere que ocorre uma diminuição da plasticidade comportamental no envelhecimento, que dificulta mudanças e adaptações, o que atinge a capacidade de reação e recuperação dos efeitos da vida, capacidade entendida como resiliência. Neste ponto, salienta-se que algumas idosas revelaram necessidade de ajuda, apoio, porém demonstram ter desenvolvido a partir de suas experiências de vida ao longo do tempo, recursos que possibilitaram a adequação de seus aspectos de personalidade às questões pertinentes ao envelhecimento.

Com relação à categoria integração do ego, identificou-se o predomínio de uma boa integração, aparecendo poucas vezes uma frágil integração. Estes aspectos denotam que as idosas do estudo possuíam boa estruturação de personalidade, com uma atual flexibilidade de superego o que possibilitou uma boa capacidade para dar conta das pressões internas e do ambiente. Ainda, observa-se predomínio de um ego saudável, o que sugere a percepção de que as questões mais fortes e negativas vinculadas ao envelhecimento não trouxeram mudanças que desencadearam um desequilíbrio emocional nas idosas pesquisadas.

Neste sentido Neri $(2001,2004)$, refere que a integridade dos processos intelectuais e da continuidade dos mecanismos de auto-regulação da personalidade é significativa para a longevidade e boa qualidade de vida na velhice. Tais mecanismos sob alguns aspectos permanecem intactos, o que garante a continuidade do funcionamento psicossocial e propicia bem-estar subjetivo ao idoso. Do mesmo modo, Papalia et al. (2006) assinalam que dentre as características do envelhecimento está a tendência à estabilidade dos traços de personalidade com a velhice. Assim, apontase que identificar nas idosas do estudo tais condições de superego e ego sinaliza um envelhecimento marcado pela integridade e pelo bom ajuste da personalidade aos eventos característicos e normativos do período vigente.

\section{CONSIDERAÇÕES FINAIS}

Este estudo demonstrou que o envelhecimento é um processo que desperta diferentes sentimentos e que as pessoas, dependendo das suas estruturas de personalidade, bem como de seu estado emocional, podem experimentá-lo de forma saudável. Contudo não é um período fácil de ser enfrentado pois desencadeia mudanças que influenciam no modo como se dará seu desfecho.

Assim partindo do estudo realizado, que objetivou analisar estados emocionais em idosas, alguns apontamentos conclusivos são pertinentes. Destacase o potencial mobilizador, instigador e de análise dos aspectos da personalidade do sujeito que se adquire através do teste TAT. No caso das idosas em questão, pode-se realizar uma compreensão psicodinâmica do funcionamento psicológico e principalmente dos estados emocionais presentes durante o envelhecimento, o que pressupõe que o teste seja adequado para investigar questões particulares da velhice.

As idosas trouxeram como temáticas principais aspectos vinculados ao meio cultural, de modo que remete pensar em questões vivenciadas por elas ao longo de suas vidas. Elas apresentaram uma visão de si em uma diversidade de papéis onde predominam suas lembranças vivendo em todos os períodos do ciclo vital, desde filhas até mulheres adultas, mães e idosas. Manifestaram como impulsos e necessidades principalmente questões relativas ao cumprimento do papel materno, com desejo de se mostrarem felizes, tendo necessidade de valorização, apoio e ajuda. Além disso, percebem-se em um ambiente inseguro, desconhecido, assustador e exigente, por vezes com falta de recursos econômicos e internos, falta de apoio familiar, por momentos calmo, em outros demonstrando tristeza, sofrimento, incompreensão e que as conduz a estados de reflexão.

O grupo estudado vive estados emocionais ambivalentes com uma mescla de sentimentos em que se evidenciam aspectos vinculados a medos, ansiedades, perdas, tristeza, solidão, dependência, desejo de apoio e ajuda, sentimento de incapacidade e preocupação, ao mesmo tempo em que buscam se mostrar contemplativas, felizes, altruístas e por vezes tranquilas.

O estudo através da análise do TAT revelou que as idosas apresentaram uma estruturação de ego saudável o que as mobiliza a levar uma vida mais integrada, ativa e dinâmica buscando interagirem em grupos. Tal aspecto sugere que as mudanças ocorridas com o envelhecimento não desencadearam, nesta amostra pesquisada, um desequilíbrio dos seus 
estados emocionais. Em relação à estruturação de superego observam-se questões de rigidez, embora tenha prevalecido no desfecho das histórias relatadas na pesquisa uma maior flexibilidade que sugere melhor adaptação às condições de vida atuais.

Neste sentido, lança-se a hipótese de que com o passar dos anos, com as experiências e as novas percepções de vida, as idosas estudadas tiveram a oportunidade de experimentar diferentes vivências emocionais que as levaram a uma maior permissividade e com isso uma flexibilidade egóica, ponto este que pode ser investigado em estudos posteriores.

Considerando os mecanismos de defesa apresentados identificou-se que são usados recursos como a repressão e a projeção de forma mais frequente para lidar com as ansiedades presentes. Entretanto, também se observou a presença de mecanismos como racionalização, idealização, identificação, fuga, formação reativa, deslocamento, sublimação, dissociação, anulação, atuação e isolamento. Essa diversidade de mecanismos de defesa pode indicar boa capacidade de adaptação a este momento de vida.

Esta pesquisa chama a atenção para o fato que embora o envelhecimento carregue consigo questões que pressupõe perdas, não são apenas estas que guiam o processo. Observou-se que nas idosas do estudo, a capacidade de administrar as contingências do envelhecimento possibilitou uma identificação dos estados emocionais em que apareceram recursos de adequação das estruturas psíquicas, ou seja, evidenciando integridade e bom ajustamento da personalidade.

Também, o estudo realizado mostrou que, neste grupo, as idosas mostraram-se com necessidade de falar de si mesmas, pois após a coleta de dados, muitas revelaram particularidades de suas vidas, que não foram registradas, mas que iriam ao encontro do que o TAT identificou em sua interpretação. Esse aspecto demonstra que seria importante em próximos estudos incluir como instrumento uma entrevista semi dirigida conjuntamente com o teste, a qual oportunizaria uma melhor compreensão dos dados coletados e uma relação com o conteúdo do TAT. Por outro lado destaca-se também que, talvez, o aspecto mobilizador do teste projetivo tenha influenciado no sentido de mobilizar nestas idosas aspectos até então reprimidos despertando a necessidade de falar sobre si mesmas. Consequentemente, emergiu um sentimento de importância nas idosas, as quais agradeciam pelo convite e oportunidade de participação no estudo, destacando que percebem hoje, por serem idosas, que é necessário dar mais atenção para às pessoas que estão nesta etapa da vida.
Este estudo despertou questões que podem ser trabalhadas em outras pesquisas tais como: estabelecer comparações de resultados de estados emocionais expressos no TAT com outras faixas etárias do ciclo vital; correlações com estados emocionais de idosas que frequentam e não frequentam grupos, bem como comparações entre a situação econômica e outras variáveis sociodemográficas.

\section{REFERÊNCIAS}

Abt, L. E., Bellak, L. (1950). Projective psychology: Clinical approaches to the total personality. New York: Alfred A. Knopf.

Aranha, V. C. (2007). Aspectos psicológicos do envelhecimento. In Papaléo Neto, M. Tratado de gerontologia ( $2^{\mathrm{a}}$ ed., rev. e ampl.) (pp. 255-265). São Paulo: Atheneu.

Argimon, I et al.(2009). As variáveis sexo e idade como fatores de vulnerabilidade para sintomas depressivos em idosos. Perspectiva (Erechim), 124(33), 17-28.

Bellak, L., Abrams, D. M. (1996). The T.A.T., the C.A.T. and the S.A.T. in clinical use (6 ${ }^{\text {th }}$ ed.). Needham Heights Ally \& Bacon.

Benoit, V. (2002). The TAT: An heuristic projective test for clinical work with the elderly subject. Psycinfo: $A P A$.

Caldas, C. P. (2007). Quarta idade: a nova fronteira da gerontologia. In.: Papaléo Neto, M. Tratado de Gerontologia. 2 ed. Revisado e Ampliado. São Paulo: Editora Atheneu,12, pp. 163-173.

Campos, E. M. P.; Bach, C. \& Alvares, M. (2003). Estados emocionais do paciente candidato de transplante de medula óssea. Psicologia: Teoria e Prática, São Paulo, 5(2). Recuperado em 27 de setembro de 2010, de http://pepsic. bvs-psi.org.br/scielo.php?script=sci_arttext\&pid=S1516$36872003000200003 \& \operatorname{lng}=$ pt\&nrm=

Capitanini, M. E. S. \& Neri, A. L. (2010). Sentimentos de solidão, bem-estar subjetivo e relações sociais em mulheres idosas vivendo sozinhas. In Neri, A. L.; Yassuda, M. S., \& Conselho Federal de Psicologia. Sistema de avaliação de testes psicológicos. Recuperado em 20 de outubro de 2010, de http:// www2.pol.org.br/satepsi/sistema/admin.cfm?lista $1=$ sim

Erné, S. A. (2000). O exame do estado mental. In Cunha, J. A. et al. Psicodiagnóstico - V (5 ed., rev. e ampl.) (pp. 67-74). Porto Alegre: Artes Médicas Sul.

Ferrari, M. A. C. (2007). Lazer, ocupação do tempo livre e os programas de terceira idade. In Papaléo Neto, M. Tratado de gerontologia (2 $2^{\mathrm{a}}$ ed., rev. e ampl.) (pp. 243-251). São Paulo: Atheneu.

Gaglietti, M., \& Barbosa, M. H. S. (2007). Que idade tem a velhice? Revista Brasileira de Ciência do Envelhecimento Humano (Passo Fundo), 4(2). Recuperado em 20 de setembro de 2010, de http:// www.upf.tche.br/seer/index.php/rbceh/article/view/131/103

IBGE. (2009). Instituto Brasileiro de Geografia e Estatística. Recuperado em 22 de setembro 2010, de http://www.ibge.gov. br/home/

Joia, L. C.; Ruiz, T., \& Donalisio, M. R. (2007). Condições associadas ao grau de satisfação com a vida entre a população de idosos. Revista de Saúde Pública (São Paulo), 41(1). Recuperado em 10 de setembro 2010, de http://www.scielo.br/scielo.php?script=sci arttext\&pid=S0034-89102007000100018\&lang=pt

Murray, H. (1995). Teste de apercepção temática: T.A.T. Tradução de José de Souza e Melo.

Neri, A. L. (2001). Paradigmas contemporâneos sobre o desenvolvimento humano em psicologia e em sociologia. In Neri, A. L. (Org.). Desenvolvimento e envelhecimento: perspectivas 
biológicas, psicológicas e sociológicas (pp. 11-37). Campinas: Papirus.

Neri, A. L. (2005). Palavras-chave em gerontologia (2 $2^{\mathrm{a}}$ ed., rev. e ampl.). Campinas: Alínea.

Neri, A. L. (2004). O que a psicologia tem a oferecer ao estudo e à intervenção o no campo do envelhecimento no Brasil, hoje. In Neri, A. L.; Yassuda, M. S., \& Cachioni, M. Velhice bemsucedida. Aspetos afetivos e cognitivos (2 $2^{\mathrm{a}}$ ed.) (pp. 13-27). Campinas: Papirus.

Organização Mundial da Saúde. (2011). Recuperado em 10 de setembro 2010, de http://www.who.int/en/

Papaléo Neto, M. (2007a). Processo de envelhecimento e longevidade. In Papaléo Neto, M. Tratado de gerontologia ( $2^{\mathrm{a}}$ ed., rev. e ampl.) (pp. 3-14). São Paulo: Atheneu.

Papaléo Neto, M. (2007b). Ciência do envelhecimento: abrangência e termos básicos e objetivos. In Papaléo Neto, M. Tratado de gerontologia ( $2^{\mathrm{a}}$ ed., rev. e ampl.) (pp. 29-37). São Paulo: Atheneu.

Papalia, D. E.; Olds, S. N., \& Feldman, R. D. (2006). Desenvolvimento psicossocial na terceira idade. In Papalia, D. E. Olds, S. N., \& Feldman, R. D. Desenvolvimento humano ( $8^{\mathrm{a}} \mathrm{ed}$.). Porto Alegre: Atmed.

Santos, F. H.; Andrade, V. M. \& Bueno, O. F. A. (2009). Envelhecimento: um processo multifatorial. Psicologia em Estudo, Maringá, 14(1). Recuperado em 10 de setembro 2010, de http:// www.scielo.br/scielo.php? script=sci arttext\&pid=S1413$73722009000100002 \&$ lang $=p t$

Shentoub, V. (Org). (1990). Manual de utilização do TAT. Paris: Climepsi Editores.

Silva, M. C. de V. M. (1989). TAT: aplicação e interpretação do teste de apercepção temática. São Paulo: EPU.

Silva, L. R. F. (2008). Da velhice à terceira idade: o percurso histórico das identidades atreladas ao processo de envelhecimento.
História, Ciência, Saúde-Manguinhos, Rio de Janeiro, 15(1). Recuperado em 10 de setembro 2010, de http://www.scielo.br/ scielo.php?script=sci_arttext\& pid=S010459702008000100009 \&lang $=\mathrm{pt}$

Silva, M. C. de V. M., \& Montagna, M. E. (2008). O teste de apercepção temática. In Villemor-Amaral, de A. E., \& Werlang, B. S. G. (Org.). Atualizações em métodos projetivos para avaliação psicológica (pp. 133-146). São Paulo: Casa do Psicólogo.

Werlang, B. G. (2000). TAT, conforme o modelo de Bellak. In Cunha, J. A. (Col.). Psicodiagnóstico - V (5 ed., rev. e ampl.) (pp. 409-415). Porto Alegre: Artes Médicas Sul.

Zimerman, D. E. (1999). Fundamentos psicanaliticos: teoria, técnica e clínica - uma abordagem didática. Porto Alegre: Artmed.

Autores:

Claudia Dallagnol - Psicóloga, formada pela Universidade Regional Integrada do Alto Uruguai e das Missões - Campus de Erechim. <claudia dallagnol@ hotmail.com>.

Eluisa Bordin Schmidt - Psicóloga Clínica, Mestre em Psicologia Clínica pela PUCRS, Professora do Curso de Psicologia da Universidade Regional Integrada do Alto Uruguai e das Missões - Campus de Erechim.

Irani I. de Lima Argimon - Doutora em Psicologia - PUCRS. Coordenadora do Grupo de Pesquisa Avaliação e Intervenção no Ciclo Vital - Pós-Graduação em Psicologia - PUCRS

Endereço para correspondência:

Claudia Dallagnol

Rua Sílvio de Marchi, 85 - Bela Vista

CEP: 99700-000 Erechim, RS, Brasil

Tel.: (54)9943-1947

E-mail: claudia_dallagnol@hotmail.com

Recebido em: 06.04.2013.

Aceito em: 21.03.2014. 